\title{
The Relationship between Extrinsic Motivators and Local Government Employee Teams' Performance in Iringa Municipal Council, Tanzania
}

\author{
Esther J. Ikasu \\ Ruaha Catholic University e.ikasu@hotmail.co.uk
}

\begin{abstract}
While it appears clear that the choice at the exposure of government institutions has been extrinsic motivation over intrinsic motivation, there is no sufficient evidence to whether extrinsic motivators contribute to higher performance of the employees in the public sector organizations. This study examined the relationship between extrinsic motivators and the performance of employees in Iringa District Council by administering a structured questionnaire over 130 team supervisors. The findings show that changes in any of the three selected forms of extrinsic motivation namely career development initiatives, improving working and employment conditions, and rewards could affect the performance of employees and their teams. However, career development initiatives and improving working conditions could have more significant effect on the performance of employees and teams. One important reason is that career development and working and employment conditions improvement arrangements were within the reach of the teams and their supervisors. On the other hand, rewards implementation could not be feasible without endorsement and approval from the central government and the top management of the council.
\end{abstract}

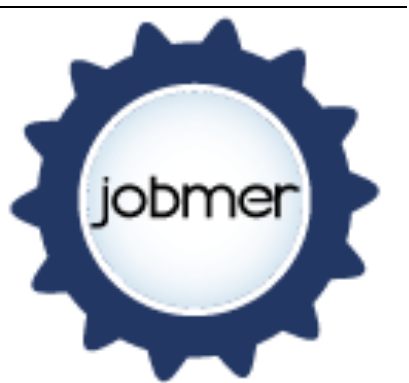

Journal of Business Management and Economic Research Vol.2, Issue.8, 2018 pp.21-37

Doi: 10.29226/TR1001.2018.55

Keywords: Extrinsic motivation, employees' performance, local government authorities, Tanzania

\section{Introduction}

The contribution of motivation in the success of organizations may not fairly be overstated. Whether a business enterprise of which the primary concern is making profit or a government department, which seeks to deliver quality goods and services to the public; setting goals and objectives which employees and managers should seek to obtain may not be a success without a feeling among individuals that they have a responsibility for the success of organizations. In this way, motivation is perceived to be major catalysts, which push employees towards attaining the goals in organizational settings (Gómez-Miñambres, 2012) and making the employees feel 
happy and desirous to contribute to the success of the organizations (Locke \& Latham, 1990).

While it is scholarly consensual that being motivated, or feeling moved to do something (Ryan and Deci, 2000) is a prerequisite for both successful goal setting and employees performance, there is little consensus on what exactly motivates individuals in the organizations. One of the reasons for this caveat has been the elusiveness of the concept itself, which is largely associated with variations on what motivates different employees in the working environments. The scholarship about motivation in working places shows that motivation is a multilevel and multiphase concept, which needs to be approached from different conceptual and theoretical angles (Liang, Wang, Wang, \& Xue, 2018). One of the important concepts in connection with these illusions has been the motivation orientation, especially the source and trigger of attitudes and goals that drive actions of individuals (Ryan \& Deci, 2000). The motivation orientation may broadly range from a personal curiosity and interest in the job and related goals to the intangible or tangible attractions associated with successful accomplishment of the goals by individual employees and teams.

There are those who conceive motivation as largely internal and psychological. Locke and Latham (1996) for instance, look at motivation as an internal force, a self-concept, or a drive for achievement that pushes the employees to identify challenging goals and work to attain them (See also Peters, 2015). Approaching motivation from this conceptual angle makes motivation an inbuilt psychological feeling, which makes the orientation towards the organizations and work differ from one employee to another and thus the need to understand what motivate different employees at individual and psychological level. On the other hand, some scholars perceive motivation as a response to external stimuli in the working environments. While they agree that motivation involves developing a positive psychological orientation towards the job, they emphasize the need to attract and cultivate the motivation of individuals using external means such as rewards and attractive working environments (Ryan \& Deci, 2000). These two competing world views makes motivation a dual concept, which is classified into two categories namely intrinsic and extrinsic motivation, which are also attributed to differing motivators generally classified as internal and external motivators.

The literature on motivation in workplaces shows a clear distinction between intrinsic and extrinsic motivation and thus sheds light for existence of alternative choices for both organizations wanting to invest in motivation of employees and researcher who try to assess the effectiveness of these alternative motivation options. The basis for distinguishing extrinsic from intrinsic motivation is the apparent goal that drives the action of an individual. While intrinsic motivation implies doing something because it is inherently interesting or enjoyable, extrinsic motivation implies doing something because it leads into a separable outcome (Ryan \& Deci, 2000). Therefore, the fact that difference in the driving goals of the actions largely determine both the quality of outcomes and possibilities of sustaining the attained level of performance under different organizational contexts is not highly contended (Vilnai-Yavetz \& Levina, 2018). 
While it is clear that motivation is important not only for business organizations but also public organizations, there are little evidence to suggest that extrinsic motivators have significantly contributed to higher performance of the employees, especially in the context of local government authorities in Tanzania. Local governments, unlike business entities or independent departments of the central governments have limited operational and financial autonomy. Therefore, any intervention which is in contradiction with the plans and strategies of the central government is likely to suffer from retribution or financial deprivation (Venugopal \& Yilmaz, 2010). Therefore, the choice of effective motivation strategies for local government needs to be thought out carefully. Against this background, this study examined the relationship between extrinsic motivators and local government employees' performance taking Njombe District Council as a case.

\section{Literature Review}

\section{The concept of motivation}

Man is characterized as a wanting animal whose actions are controlled by the fulfillment of his wants (McGregor, 1960). This means that as human beings, we rarely act if there is no motivation behind human actions. As far as performance of employees is concerned, there must be something either within or outside the employee's that drives them to respond to their job responsibilities in a way they do. This drive is what the concept motivation represents in the theory and practices related to human resources and employment management.

In general terms, motivation can be defined as the force that drives an individual to do something. It can also imply the reason to act or behave in a certain way (Shaun \& York, 2006). As also defined by Pardee (1990), from a psychological perspective it is a reason that drives actions, desires, and needs of the people or ones direction of behavior that makes an individual consistently want to repeat behaviour. What drives actions and behaviour can be either within or out of an individual. Internally driven actions and behaviours are said to be driven by internal motivation or intrinsic motivation. On the other hand, when actions or behaviour are caused by external driving force, this force is identified as external or extrinsic motivation (Armstrong, 2009).

When one talks about motivation in working places, it reflects the idea of liking to fulfill ones job or contribute to the attainment of organizational goals and objectives (Locke, 1996). However, clarity is needed when one talks about motivation in the working places since there is a suggested hierarchy of motivating forces which are dynamic and interdependent. For example, while it is claimed that external physical motivators are basic and they must be there to make employees feel safe and fulfill their responsibilities, there is an observation that once fulfilled, the employees will always move up the hierarchy and think about internal motivators such as freedom and participation in decision making (Armstrong, 2009). However, this study was more concerned with external motivators, which must be provided by the employer to attract higher performance of employees and teams in working places (Gupta, 1980). Being the case, despite acknowledging the importance of intrinsic motivation as a way 
of sustaining higher performance work behavior among individuals and teams, the assumption was that extrinsic motivation is a necessity. In other words, the attraction to contribute towards fulfillment of organizational objectives is primarily embedded in the perceptions of the outcomes of accomplishing such objectives rather than personal satisfaction and enjoyment, which is associated with the work itself.

\section{What constitutes extrinsic motivation?}

In career psychology, extrinsic motivation is taken as the act of doing something because of existence or expectation of an external reinforcement. This implies that there must be an external stimulus that attracts employees to adopt certain job behavior and invest a certain level of efforts aimed at fulfilling the task required of them (Locke \& Latham, 1990). 'Reinforcement', generally connotes anything that attracts performance and positive work behavior from outside employees' internal driving forces such as enjoying work, the desire to learn new things, and success dreams (Ryan \& Deci, 2000; Vilnai-Yavetz \& Levina, 2018). It therefore, includes material and immaterial incentives that motivate employees to do work where employees take actions related to the job not because of the job itself, but the outcome of doing that job on him/her.

There are some common extrinsic motivations that employers use to make employees improve performance in work places. For the p[purpose of this study, extrinsic motivators are identified and discussed under three categories, especially Career Development Initiatives (CDIs), Working and Employment Conditions (WECs), and Reward for Performance (R4P).

\section{Career Development Initiatives (CDIs)}

Career development (and strengthening) is both an internal and external process. While the literature on psychology treats career development as a result of motivation, it is increasingly becoming established that career development is a strong tool for motivating employees (Stumpf; Colarelli; \& Hartman, 1983). CID includes a variety of programs, strategies, processes, and practices that employers put in place to support career choices and career decisions that allow employees to grow and succeed. It includes the provision of information available for advancing skills and competences and creating opportunities for employees to pursue and utilize available career growth opportunities and supporting employees personal development efforts (Lerner \& Schulenberg, 1986). While the need to advance ones career is internal, external support is highly needed to make an employees and teams move up the career ladder.

Career development initiatives stand as one of the extrinsic motivators when employers intentionally decide to open up opportunities for individuals and teams in working place to develop and work towards attaining their career dreams (Templer \& Cawsey, 1999. In this study, career development initiatives is defined as rational interventions by employers that aim at facilitating and supporting employees in the processes of identifying and utilizing short and long terms job and skills enhancement opportunities to fulfill their employment and socioeconomic dreams. It therefore includes both on job and off job learning, training and professional development, and 
encouragement of innovations and creativity in the fulfillment of employee's responsibilities.

\section{Working and Employment Conditions (WECs)}

Working conditions, closely related to employment conditions refers to the physical and circumstantial environments ion which employees carry out their day-to-day job responsibilities. In its broad sense, employment conditions takes into account additional aspects that affects the employment in a particular sector or place such as labour laws and employment standards (Kogi, Phoon \& Thurman, 1989). However, something that is common about working and employment conditions is that they both explain the environments and contexts that surround the job and its fulfillment.

While the two are closely related and identified as important extrinsic motivation forces, there is a slight difference between working conditions and employment conditions. Working conditions relate to the physical and social environments in which the job is carried out such as working space, health and hygiene, occupational safety, technology, and workplace infrastructure (MacKay, 1971). On the other hand, employment conditions refer to the terms that regulate the working relationship between an employer and employee in terms of the expectations and obligations of each of the parties (Bartley, Sacker, \& Clarke, 2004). Employment conditions are presumed to arise from contractual terms, which both the employer and employee agree to (Benach, Muntaner \& Santana, 2007). This may not necessarily be a case with working conditions as they may improve or deteriorated at any time depending on different factors including resources availability or workplace leadership and management. For the purpose of this study, working and employment conditions are generally defined to include the physical and social conditions that affect the process of carrying out the job including both contractual and emergent terms and conditions under which the employees work.

\section{Rewards for performance (R4P)}

The term rewards has both a broad and narrow definitions. As used by Bratton \& Gold (2017), the broad conception includes career development and improving working conditions as forms of rewards. In a narrow sense, rewards entails only financial and non-financial incentives provided to employees based on their performance (Lawler, 2003). Rewards constitute a significant part of what is recognized as extrinsic motivation in workplaces. There are two forms of rewards, especially financial and non-financial rewards. Financial rewards include financial benefits, which employers provide to individual employees and teams depending on the outcome of their efforts such as bonuses, profit sharing, performance-based gratuities and offers.

On the other hand, extrinsic non-monetary rewards refer to the social rewards with regard to the job, which the employers facilitates. Invitation to a party or dinner event, offering a travel, or creating relaxation and leisure occasions for well performing employees' or teams are examples of performance based rewards. Rewards as used in this study includes financial benefits such as bonuses and profit sharing as well as non- 
monetary returns such as recognition for better performance, travel offers, and other material incentives offered to employees as a result of good performance.

\section{What is employees' performance?}

Employees' performance is an important measure of the extent to which the efforts of individuals in the organizations contribute to successful attainment of the desired objectives. While it is common in work places to assess the performance of teams, units, or organizations (Armstrong, 2014), the idea of performance is basically measured at individual level (Campbell, 1990). It defines the relationship between what employees can do and what they actually do in workplaces (Murphy, 1990). The idea here is that employees' performance is never standard. It is dynamic where employees should be expected to perform both below and above what they are capable of achieving depending on the efforts on the side of an employer and employees themselves to attain the highest possible levels of performance.

In this study, job performance is conceived as the amount of efforts that employees invest in the job in relation with the expected fulfillment of the goals of individuals and teams in the workplace. It is assumed that job satisfaction and motivation, which depend on the level of motivation by employees and teams determine the extent to which they will contribute to the fulfillment of the performance goals and targets before them (Meyer \& Herscovitch, 2001; Sulsky, 1999). Therefore, building highly performing teams in work places requires the managers and supervisors to play a leading role in creating environments for increasing job satisfaction and increasing commitment among teams and individuals.

\section{Relationship between extrinsic motivators and employees' performance}

Broadly conceived, the literature on the relationship between motivation and performance does not look at performance as a product of motivation alone. The most basic triggers of performance before one thinks about motivation are the abilities and experiences of individual employees (Murphy, 1995), which may indeed exist without having in place rational motivation arrangements in the working place. Individuals' competences and talents are therefore key for the performance of those individuals and their teams.

The literature on motivation and performance appears to support the view that motivation and performance are related. Motivation is identified as an important prerequisite for building highly performing organizations since it helps organizations to make employees release the potential that exists within them including skills, innovation, experience, and other competencies (Meyer \& Herscovitch, 2001; Sulsky, 1999). However, while performance is identified as the end, motivation to perform and satisfaction which explains the attitude of employees and teams towards the organizations, workplaces, and the job itself are identified as the means towards attaining performance as an end (Judge, Thoresen, Bono \& Patton, 2001). Therefore, motivation, especially extrinsic motivation which deals with creating environments for motivating employees is a critical factor for realizing higher performance. 
Taking into account this nature of relationship between extrinsic motivation and performance, three variables under extrinsic motivation, which are expected to influence the performance of employees and teams were selected for the study. The three variables are Career Development Initiatives (CDIs), improving Working and Employment Conditions (WECs), and Reward for Performance (R4P). The conceptual framework in figure 1 represents the hypothesized relationship between the three selected independent variables (CDIs, WECs, and R4P) and performance of employees and teams, which is the dependent variable.

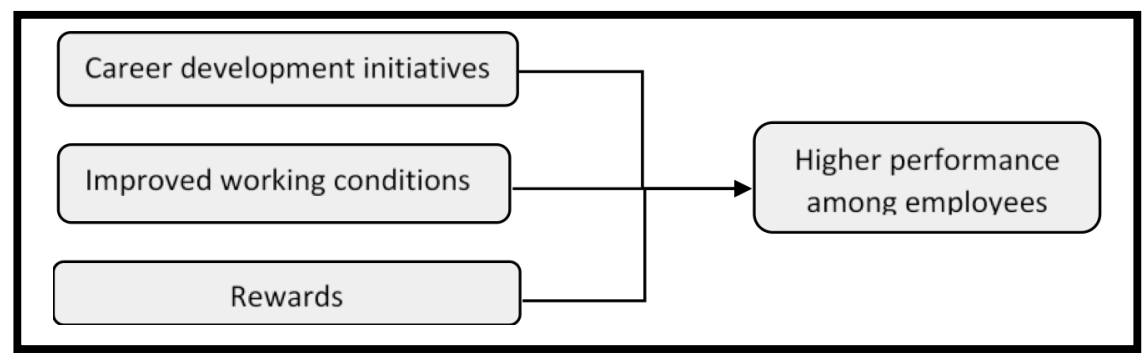

Figure 1: Conceptual framework for relationship between extrinsic motivation and employees' performance

Based on the conceptual framework, the hypotheses that follow explain the assumed relationship between CDIs, WECs, and R4P on one hand and performance of employees and teams on the other hand.

\section{Study hypotheses}

The null hypothesis ( $\left.H_{0}\right)$ : Extrinsic motivations are not significantly associated with employees' job performance.

Hypothesis $\left(\mathrm{H}_{1}\right)$ : There is a statistically significant relationship between career development initiative (CDI) and employees' performance.

Hypothesis $\left(\mathrm{H}_{2}\right)$ : There is a statistically significant relationship between improved working and employment conditions (WEC) and employee's performance

Hypothesis $\left(\mathrm{H}_{3}\right)$ : There is a statistically significant relationship between rewards and employees performance.

\section{Methods}

\section{The design}

This study adopted a cross-sectional analytical research design. A cross-sectional analytical design is appropriate for examining relationship between phenomena as they exist at a given point in time rather than the changes overtime (Creswell et al, 2013). Rather than describing in details, the characteristics of phenomena and their essence, analytical cross-sectional studies focus on whether there is any association between variables, in this case being extrinsic motivation and employees' performance. The choice of the design was mainly based on the intention of the study, which was to test the hypothesized relationship between extrinsic motivation and performance of the employees. The study was limited to a single local government authority, Njombe 
district council to control the possible effects of other intervening variables including social and cultural norms, economic endowment, and local administration politics, which may affect the performance of employees in local government authorities.

\section{Study population and sampling}

The study targets were local government employees in Iringa Municipal Council. However, to identify the existence of extrinsic motivation efforts and rate the performance, the teams in working places were the focus. Therefore, the respondents had to be team leaders in the working place who were at least at supervisory level. The inclusion criteria was that the institution had to be contactable by phone to make appointment for the visit, had to have a supervisor who had supervised the team for at least one year and thus understood issues related to motivation and the performance of the team.

A total of the 200 institutions, which were delivering primary services were sampled from the five service clusters in the sample. However, only $136(68 \%)$ were physically available during the day of visitation and thus participated in the study. The five service clusters were primary health care $(\mathrm{N}=54)$, education $(\mathrm{N}=53)$, livestock $(\mathrm{N}=17)$, agriculture $(\mathrm{N}=5)$, and community development $(\mathrm{N}=7)$. A table of random numbers was used to select the required number from each of the clusters who were then contacted to confirm that they could be available during the visit. Respondents who had confirmed to be available during the visitation were contacted three times before they could be dropped from the study. This happened manly to the respondents in the clusters whose supervision involved field travels and their reachability was limited in most cases.

\section{Design and execution of the study questionnaire}

A structured survey questionnaire with 17 close ended questions was developed and used to collect data from the selected respondents. The language of the questionnaire was Kiswahili, which all the participants could understand and speak. The questionnaire was administered by the researcher who asked the questions and recorded the response that the respondents provided. The questions were pretested using seven respondents at the district council to ensure that the questions could be understood consistently after which the revisions were made to make the rating scales consistent. For example, the researcher replaced the rating out of 100 with out of 10 for all the four questions, which needed respondents to rate their teams. This helped to increase the consistence in the rating scales across the variables.

The questionnaire had 12 questions divided into two' main parts. The first part included questions on the demographic identification characteristics of the respondents including gender, age, and level of education, department, and experience of serving in the council and employees' supervision function. The four last questions were included to allow the respondents to rate their teams in terms of having extrinsic motivation efforts and the general performance of the teams, which was done by giving the team a score between one and 101 being the lowest and 10 being the 
highest. The administration of each questionnaire took between 20 and 25 minutes including the time for establishing rapport.

\section{Data analysis and statistics}

The analysis of data started with the coding and entry of the data for processing with the SPSS version 23 statistical package software. The dataset was processed to generate descriptive statistics mainly the frequency distributions, which were manually examined to compare the responses on different study variables. For the purpose of testing the hypotheses, the scores mean scores for each of the variables were calculated and the data were recoded to assign the scores on each of the variables into two categories, especially scoring above the average and below the average. The reject or accept the hypotheses were based on both the proportion between scoring high and low on one hand and the t-test of independence where the critical value for the probability that the null hypothesis could be rejected was $p<0.005$. The results of the study are presented in the next subsections.

\section{Results and Discussion}

\section{Results}

The results are presented under three main sections. The first one focuses on the social demographic characteristics of the respondents. The second one provides a descriptive analysis of the scores for the three extrinsic motivation variable as well as performance, which is the dependent variable. The third focuses on the presentation and analysis of the results from hypothesis testing, which employed the t-test of independence.

\section{Respondents' characteristics}

This study included 136 respondents who were holding leadership and supervisory positions in different sectors within Iringa municipal Council. Table 1 summarizes the key social demographic characteristics of the study respondents by gender, age, levels of education, departments, and years of experience in their employment. 
Table 1: Respondents' social demographic characteristics ( $N=136)$

\begin{tabular}{|c|c|c|c|c|}
\hline Variable & Categories & $n$ & (\%) & Total \\
\hline \multirow[t]{2}{*}{ Gender } & Male & 72 & (52.9) & \\
\hline & Female & 64 & (47.7) & $=136$ \\
\hline \multirow[t]{6}{*}{ Age } & 20.xears or less & 6 & $(4.4)$ & \multirow[b]{6}{*}{$=136$} \\
\hline & $21-25$ years & 13 & $(9.6)$ & \\
\hline & $26-30$ years & 19 & $(14.0)$ & \\
\hline & $31-35$ years & 16 & (11.8) & \\
\hline & $36-40$ years & 32 & (23.5) & \\
\hline & $41-45$ years & 31 & (22.8) & \\
\hline \multirow{5}{*}{$\begin{array}{l}\text { Highest } \\
\text { education }\end{array}$} & Above 45 & 19 & $(14.0)$ & \multirow[b]{5}{*}{$=136$} \\
\hline & Secondary education & 62 & (45.6) & \\
\hline & Diploma level & 48 & (35.3) & \\
\hline & University degree & 23 & (16.9) & \\
\hline & Postgraduate studies & 3 & $(2.2)$ & \\
\hline \multirow[t]{5}{*}{ Department } & Health & 53 & $(39.0)$ & \multirow{5}{*}{$=136$} \\
\hline & Livestock & 17 & (12.5) & \\
\hline & Agriculture & 5 & (3.7) & \\
\hline & $\begin{array}{l}\text { Community } \\
\text { Development }\end{array}$ & 7 & (5.1) & \\
\hline & Education & 54 & $(39.7)$ & \\
\hline \multirow{5}{*}{$\begin{array}{l}\text { Years } \\
\text { experience }\end{array}$} & 5 years or less & 21 & $(15.4)$ & \multirow{5}{*}{$=136$} \\
\hline & 6-10 years & 58 & (42.6) & \\
\hline & $11-15$ years & 40 & $(29.4)$ & \\
\hline & $16-20$ years & 7 & (5.1) & \\
\hline & 20 years and above & 10 & (7.4) & \\
\hline
\end{tabular}

The statistical results in Table 1 show that 72 (52.9\%) were male while 64 (47.7\%) were female respondents, which closely reflected the gender ratio of employment in the district council. The age of respondents ranged from 20 to 50 years with a mean age of 36.672 years. Many of the respondents 63 (46.3\%) were aged between 36 and 45 . In terms of education, a good majority $110(80.9 \%)$ had either secondary $(45.6 \%)$ or diploma (35.3\%) education. Only $26(19.1 \%)$ had university degree education. In terms of the departments, a significant majority 107 (78.9\%) were employed in the health $(39.0 \%)$ and education (39.9\%) departments, which constitute close to $90 \%$ of the workforce in the district council. In terms of experience in their employment, the majority $58(42.6 \%)$ had a six to 10 year experience followed by $40(29.4 \%)$ who had an 11 to 15 year experience. Overall, the majority of the respondents had rich experience on motivation and employment conditions in the district council and particularly their working places and teams.

The study also sought to find out whether the differences in the age, education, and working experience of the team supervisors had relationship with the identified performance of their teams. The age of the team supervisors was positively associated with the performance of their teams $(p=0.020)$. For example, $74.0 \%$ of the teams, which had team leaders who were below 35 years of age were performing below the average while $26.0 \%$ were performing above the average. $54.9 \%$ of the teams, which had 
supervisors who were aged above 35 years against to 45.1 were performing below the average. On the other hand, the team supervisors' level of education $(p=0.130)$ and working experience $(p=.565)$ were not significantly associated with team performance.

\section{Extrinsic motivation and performance status}

The status of extrinsic motivation differed across the 130 studied teams. In terms of career development initiatives, the scores ranged between 1.0 and 9.9 with majority of the teams scoring between 4.8 and 6.5. Majority of the companies 73 (53.7\%) scored above the average score, which was 5.77 (out of 10) while 63 (48.3\%) scored below the average. The median score was 6.0 with many of the teams, $16(11.8 \%)$ scoring 5.0, which implies that despite being below the average, many of the teams had moderate initiatives.

In case of working and employment conditions, the mean score was 6.182 out of 10 . More than half the teams $71(52.2 \%)$ scored below the average while a closely equal proportion $65(47.8 \%)$ scored above the average. Reward for performance, the mean score was 5.132 out of 10 . However, there were some slight difference across the teams where $66(48.5 \%)$ of the teams scored above the average while $70(51.5 \%)$ of the teams scored below the average.

In terms of the overall performance of the teams, the there were differences across the teams with the lowest score of 3 and the highest score of 10 (out of 10). While the mean score for all the teams was 6.054 , which is relatively high, the majority of the teams 85 $(62.5 \%)$ were below the average and $51(37.5 \%)$ were above the average. The forthcoming sections tests the hypothesis to show the relationship between the three selected extrinsic motivation variables and the performance of the employees in the studied teams.

\section{Hypothesis testing and analysis}

Three hypotheses relating to the relationship between extrinsic motivation and employees' performance were tested. The hypothesized relationship was between three selected extrinsic motivators and employees' performance. These were career development (initiatives), working conditions, and rewards for performance. On the other hand, the null hypothesis was that EXTRINSIC motivation is not significantly associated with employees' performance. The t-test statistical was used to compare the mean scores between the teams, which had scored below the average (low performance teams) and those that had scored above the average (referred as high performance teams).

A summary of statistical results is presented in table 2 . 
Esther J. Ikasu, 2018, Vol.2, Issue.8, pp.21-37

Table 2: t-test statistical results

\begin{tabular}{|c|c|c|c|c|}
\hline $\begin{array}{l}\text { varia } \\
\text { ble }\end{array}$ & Performance score categories & $\mathrm{n}(\%)$ & t-value & p-value \\
\hline \multirow[t]{2}{*}{ CDI } & Below the average score $(<6.054)$ & $\begin{array}{l}\text { 63(46.3 } \\
\%)\end{array}$ & \multirow[b]{2}{*}{-4.078} & \multirow[b]{2}{*}{.000} \\
\hline & Above the average $(>6.054)$ & $\begin{array}{r}73(53.7 \\
\%)\end{array}$ & & \\
\hline \multirow[t]{2}{*}{ WEC } & Below the average score $(<6.054)$ & $\begin{array}{r}71(52.2 \\
\%)\end{array}$ & \multirow[b]{2}{*}{-4.414} & \multirow[b]{2}{*}{.000} \\
\hline & Above the average $(>6.054)$ & $\begin{array}{c}65(47.8 \\
\%)\end{array}$ & & \\
\hline \multirow[t]{2}{*}{$\mathrm{R} 4 \mathrm{P}$} & Below the average score $(<6.054)$ & $\begin{array}{r}70(51.5 \\
\%)\end{array}$ & \multirow[b]{2}{*}{-3.010} & \multirow[b]{2}{*}{.003} \\
\hline & Above the average $(>6.054)$ & $\begin{array}{r}66(48.5 \\
\%) \\
\end{array}$ & & \\
\hline
\end{tabular}

Hypothesis $1\left(\mathrm{H}_{1}\right)$ : There is a statistically significant relationship between career development and employees performance.

The first hypothesis was on the statistical relationship between career development initiatives and employees' performance. The statistical results indicated the existence of statistically significant relationship between career development initiatives and employees performance. The negative t-value as indicated in table 2 shows that there is a reverse in the directionality of the relationship between having in place career development initiatives and the performance of teams. The p-value on the other hand $\mathrm{p}<0.005)$ indicates the existence of statistically significant difference between having career development initiatives, which are below and above the average $(t=4.78, p=000)$. Therefore, the results show that there is a statistically significant relationship between career development initiatives and performance of the teams, which implies that changes in career development initiatives will significantly alter the performance of the teams and their employees. With these results, the hypothesis that there is statistically significant relationship between career development and employees' performance is accepted.

Hypothesis $2\left(\mathrm{H}_{2}\right):$ There is a statistically significant relationship between improved working conditions and employees' performance

In relation with the second study hypothesis, which was on the relationship between working and employment conditions and employees' performance, the results similarly indicated the existence of statistically significant relationship between working and employment conditions on one hand and the performance of employees $(\mathrm{t}=-4.414, \mathrm{p}=0.000)$. With the $\mathrm{p}$-value of 0.000 , the results show that the difference between having a score above or below the average (6.054) is statistically associated with the variations in the scores on the general performance of the teams. With these 
results, the hypothesis that there is a statistically significant relationship between the working and employment conditions and employees' performance is accepted. These results indicate that changes that could improve or negatively affect working and employment conditions will necessarily affect the performance of the teams.

\section{Hypothesis $3\left(\mathrm{H}_{3}\right)$ : There is a statistically significant relationship between rewards and employees performance.}

The third study hypothesis was on the relationship between rewards for performance and improvement in the performance of employees in the teams. Majority of the teams scored lower than the average score on both reward for performance arrangements and the performance of the teams. However, the statistical results from the t-test indicated existence of statistically significant relationship between rewards for performance and employees' performance $(t=-3.010, p=0.003)$. The $p$-value, $p<0.003$ indicates the existence of statistically significant relationship between the differences in reward for performance and the performance of the teams. Based on these results, the hypothesis that there is a statistically significant between rewards and employees' performance is accepted, which means that improvements or deterioration in reward arrangements may significantly cause variations in the performance of the studied teams.

Despite some variations across all the three hypotheses, the results indicate the existence of relationship between the selected extrinsic motivation variables and employees' performance. In the light of these findings, it can be argued that focusing on the extrinsic motivation of the employees is significant for altering the performance of the teams in the work places.

\section{General discussion}

The findings have generally indicated that extrinsic motivation is significantly related to the performance of employees and teams in local government authorities. However, it has been demonstrated that investing in career development initiatives could significantly affect the performance of employees and teams. This is probably because career development initiatives and improving working and employment conditions are motivation strategies, which are within the control of the supervisors and their teams (Lerner \& Schulenberg, 1986). Apart from the commitment by employers and managers, employees have an important contribution towards successful career development motivation strategies since career development may take varying approaches including employee-centered initiatives (Templer \& Cawsey, 1999. In participatory and employees' centered models, the employees are likely to become effective players and leaders of the process who are responsible for self-motivation.

Reward for performance had the least, but significant relationship with performance of teams and employees. This could be an indication that compared to instituting career development programs and improving working conditions, provision of rewards may not significantly alter the performance of employees because of the limited control of the workplace teams on rewards arrangements and their outcomes. As it has been revealed by the previous research by Kloot \& Martin (2000) the limited capacity of local 
governments to beat the budgets in favor of performance management support initiatives affect the effectiveness of performance management among employees in local governments. This is because implementing reward for performance initiatives need the organizations and their managers to have sufficient resources for providing incentives to employees and teams, which perform well (Melkers \& Willoughby, 2005). Resources allocation is an important factor in both extrinsic motivation and performance management without which rewards for performance may not be easy to institute as an extrinsic motivation strategy.

Another explanation in favor of career development initiatives as a way of motivating employees as to do with the constraints resulting from the limited financial and managerial autonomy among local government authorities and their institutions. As Kogi, Phoon, \& Thurman (1989) argue, the choice for successful motivation strategies need to take into account the easiness and cost-effectiveness of the strategies in relation with the human and financial capacity of the organization. In situations the workplace teams and their supervisors do not have powers to make decisions and implement decisions related to the provision of incentives to the best performing employees and teams, the reward for performance as an extrinsic motivation strategy may have a limited practicability.

\section{Limitations and future research}

There were two main limitations that need to be acknowledged in this study. The first limitation related to limiting the study to a single district. Despite having representation of different sectors from Iringa municipal council, the social, political, and economic contexts of the municipal may not necessarily be similar to other municipal in the country. Therefore, the findings may only provide lessons for related institutions in other municipal, which are similar to Iringa municipal Council. Related to the first, the second limitation concerns the use of quantitative data only, which aided for reaching the conclusion that this study reached. The researcher recognizes that the use of quantitative data abstracted the possibility of generating rich insights based on the lived experiences of the respondents who had for long worked as supervisors of the studied teams. In this respect, it is important to conduct further studies, which should utilize the advantage offered by both qualitative and quantitative methods to explore how the autonomy in decision making affects the capacity of local government institutions to initiate, establish, and implement employees' motivation and reward systems.

\section{Implication and Conclusion}

The aim of the study was to examine the relationship between extrinsic motivation and performance of employees in the local government focusing on career development initiatives, working and employment conditions, and rewards. The analysis of the three hypotheses has revealed that changes in extrinsic motivation practices may have significant effect on the performance of both employees and their teams. While the differences in the supervisor's demographic characteristics did were not found to have significant moderating effect on the relationship between extrinsic motivation and performance, investing in extrinsic motivation in the work places has a potential of 
improving performance of employees' teams regardless of the differences in the team supervisors competencies and professional maturity.

Based on the results and discussion in the earlier sections, the study concludes that encouraging team supervisors in the local government authorities to employ a variety of extrinsic motivation strategies at their exposure may lead into significant improvements in employees' and team performance. It is therefore imperative to support the capacities of team supervisors in the work place to strategize, plan out, and initiate cost-effective extrinsic motivation initiatives which are within control of their own teams instead of giving priority to strategies and motivation interventions that cannot be implemented without programmed financing and approval by the central government or the council management. Initiatives for encouraging employees to use available career development opportunities and participatory efforts for improving working and employment conditions for individual workplaces and teams appear to be the most feasible option in the quest to using extrinsic motivation to improve performance of the employees in local government authorities.

\section{Reference}

Armstrong, M. \& Taylor, S. (2014). Armstrong's Handbook of Human Resource Management Practice, New Delhi: Kogan Page Publishers

Armstrong, M. (2009). A Hand book of Human Resource Management Practices, London: Cambridge University Press.

Bartley, M., Sacker, A., \& Clarke, P. (2004). Employment status, employment conditions, and limiting illness: prospective evidence from the British household panel survey 1991-2001. Journal of Epidemiology \& Community Health, 58(6), 501-506.

Benach, J., Muntaner, C., \& Santana, V. (2007). Employment conditions and health inequalities. Toronto: Centre for Addiction and Mental Health (CAMH)University of Toronto

Bratton, J., \& Gold, J. (2017). Human resource management: theory and practice. London: Palgrave.

Campbell, J. P. (1990). Modeling the performance prediction problem in industrial and organizational psychology. In M. D. Dunnette \& L. M. Hough (Eds.), Handbook of Industrial and Organizational Psychology. Palo Alto, CA: Consulting Psychologists Press, Inc.

Creswell, J. (2012). Educational Research; Planning, Conducting and Evaluating Quantitative and Qualitative Research. Boston USA: Pearson.

Creswell, J. W., Klassen, A. C., Plano Clark, V. L., \& Smith, K. C. (2011). Best Practices for Mixed Methods Research in the Health Sciences. Bethesda, MD: National Institutes of Health, 10.

Ghaffari, S., Shah, I. M., Burgoyne, J., Nor, M., Bin, M. N., \& Salleh, J. R. (2017). The Influence of Motivation on Job Performance: A Case Study at Universiti Teknoligi Malaysia, Australian Journal of Basic and Applied Sciences, 11(4), 92-99 
Gómez-Miñambres, J. (2012). Motivation through goal setting, Journal of Economic Psychology 33, 1223-1239

Gupta, P.K. (2010). Human Resources Management, New Delhi: Dreamtech Press

Jepsen, D.A., \& Dickson, G.L. (2003). Continuity in life-span career development: career exploration as a precursor to career establishment. Career Development Quarterly, 51(3), 217 - 233.

Judge, T. A., Thoresen, C. J., Bono, J. E., \& Patton, G. K. (2001). The job satisfaction-job performance relationship: A qualitative and quantitative review. Psychological bulletin, 127(3), 376.

Kloot, L., \& Martin, J. (2000). Strategic performance management: A balanced approach to performance management issues in local government. Management Accounting Research, 11(2), 231-251

Kogi, K., Phoon, W. O., \& Thurman, J. E. (1989). Low-cost ways of improving working conditions: 100 examples from Asia. International Labour Office.

Lawler, E. E. (2003). Reward practices and performance management system effectiveness. Organizational Dynamics, 32(4), 396-404.

Lerner, R. M., \& Schulenberg, J. E. (1986). Career development: A life-span developmental approach. Mahwah: Lawrence Erlbaum.

Liang, H., Wang, M. M., Wang, J. J., \& Xue, Y. (2018). How intrinsic motivation and extrinsic incentives affect task effort in crowdsourcing contests: A mediated moderation model. Computers in Human Behavior, 81, 168-176.

Locke, E. A. (1996). Motivation through conscious goal setting, Applied \& Preventive Psychology, 5, 117-124.

Locke, E. A., \& Latham, G. P. (1990). Work motivation and satisfaction: Light at the end of the tunnel, Psychological Science, 1, 240-246.

MacGregor, D. (1960). The human side of enterprise (Vol. 21, No. 166.1960). New York.

MacKay, D. I. (Ed.). (1971). Labour markets under different employment conditions (No. 22). G. Allen \& Unwin

Melkers, J., \& Willoughby, K. (2005). Models of performance-measurement use in local governments: Understanding budgeting, communication, and lasting effects. Public Administration Review, 65(2), 180-190

Meyer, J. P., \& Herscovitch, L. (2001). Commitment in the workplace: Toward a general model. Human resource management review, 11(3), 299-326.

Murphy, K. R. (1990). Job performance and productivity. Psychology in organizations: Integrating science and practice, 157, 176.

Murphy, K. R., \& Kroeker, L. P. (1988). Dimensions of job performance. Fort Collins: Colorado State University

Nujjoo, A., \& Meyer, I. (2012). The relative importance of different types of rewards for employee motivation and commitment in South Africa. SA Journal of Human Resource Management, 10(2), 1-10

Pardee, R. L. (1990). Motivation Theories of Maslow, Herzberg, McGregor \& McClelland. A Literature Review of Selected Theories Dealing with Job Satisfaction and Motivation.

Peters, R. S. (2015). The concept of motivation. London: Routledge 
Pinder, C. C. (1984). Work motivation: Theory, issues, and applications. Illinois: Scott Foresman \& Co.

Puah, P., \& Ananthram, S. (2006). Exploring the antecedents and outcomes of career development initiatives: Empirical evidence from Singaporean employees. Research and practice in human resource management, 14(1), 112-142.

Ryan, R. M., \& Deci, E. L. (2000). Intrinsic and extrinsic motivations: Classic definitions and new directions. Contemporary educational psychology, 25(1), 54-67

Shaun, T., \& York, A. (2006). Essentials of Human Resource Management. Toronto: Elsevier Limited.

Stumpf, S. A., Colarelli, S. M., \& Hartman, K. (1983). Development of the career exploration survey (CES). Journal of Vocational Behavior, 22(2), 191-226.

Sulsky, L. M. (1999). Review of Commitment in the workplace: Theory, research, and application. Canadian Psychological Association, 40 (4), 383

Venugopal, V., \& Yilmaz, S. (2010). Decentralization in Tanzania: an assessment of local government discretion and accountability. Public Administration and Development, 30(3), 215-231

Vilnai-Yavetz, I., \& Levina, O. (2018). Motivating social sharing of e-business content: Intrinsic motivation, extrinsic motivation, or crowding-out effect? Computers in Human Behavior, 79, 181-191. 